DOI: https://doi.org/10.17648/2238-037X-trabedu-v28n3-9854

\title{
A INTERFERÊNCIA DO EMPRESARIADO NAS POLÍTICAS PARA A EDUCAÇÃO DO TRABALHADOR ${ }^{1}$
}

\author{
The entrepreneur interference in policies for worker education
}

\author{
LEME, Renata Bento ${ }^{2}$ \\ RUIZ, Maria José Ferreira ${ }^{3}$ \\ GARCIA, Sandra Regina de Oliveira ${ }^{4}$
}

\begin{abstract}
RESUMO
Este artigo, por meio de pesquisa bibliográfica e documental, tem o objetivo de apresentar os caminhos históricos que levaram o atual governo federal a sancionar a Lei n. 13415/2017, da reforma do ensino médio. Objetiva ainda discutir a tendência histórica da interferência dos empresários na elaboração das políticas educacionais, voltadas para o ensino médio e para a educação profissional, no Brasil. Apresenta indícios destas interferências desde a elaboração da Lei Capanema, passando pelo período ditatorial, em que a profissionalização compulsória foi colocada em prática por meio da Lei n. 5692/1971. No processo de elaboração da LDBEN/1996, o ideário neoliberal reitera a prioridade de preparar o sujeito para as exigências do mundo da produção. A partir de 2006, com a instituição do movimento empresarial "Todos Pela Educação", a influência deste grupo torna-se mais orgânica e ocorre em parceria com o MEC e entidades como o CONSED, obtendo forte presença na elaboração das diretrizes para a reforma do ensino médio. Conclui destacando que as políticas para a educação, historicamente, são elaboradas em um contexto de disputa entre projetos muito diferentes de sociedade e mediatizadas pelos confrontos entre as classes antagônicas. Assim, reforçam a oferta de uma educação para formação da força de trabalho que atenda aos interesses do empresariado e se afastam do ideal de formação humana e plena dos sujeitos sociais.
\end{abstract}

Palavras-chave: Política Educacional. Ensino Médio. Educação Profissional.

\begin{abstract}
This article, through bibliographical and documentary research, aims to present the historical paths that led the current federal government to sanction Law n. 13415/2017, of the reform of high school. It also aims to discuss the historical trend of entrepreneurs' interference in the elaboration of educational policies, aimed at secondary education and professional education, in Brazil. It presents indications of these interferences from the elaboration of the Capanema Law, passing through the dictatorial period, in which compulsory professionalization was put into practice through Law 5692/1971. In the process of elaborating LDBEN/1996, the neoliberal ideology reiterates the priority of preparing the subject for the demands of the world of capitalist production. Since 2006, with the establishment of the "All for Education" business movement, the influence of this group becomes more organic and occurs in partnership with the MEC and entities such as CONSED, obtaining a strong presence in the
\end{abstract}

\footnotetext{
${ }^{1}$ O texto tem financiamento da Coordenação de Aperfeiçoamento de Pessoal de Nível Superior (CAPES), no fomato de Bolsa de demanda Social.

${ }^{2}$ Mestre em Educação pela Universidade Estadual de Londrina - UEL, Graduação em Pedagogia pela UNESP/Marilia. Bolsista da Coordenação de Aperfeiçoamento de Pessoal de Nível Superior CAPES. E-mail: rb.leme@yahoo.com.br .

${ }^{3}$ Pós Doutora em Educação pela UFRGS, Doutora em Educação pela UNESP/Marília, mestre em Educação pela Universidade Estadual de Londrina- UEL, Graduação em Pedagogia, pela UEL. Professora do curso de Pedagogia, na área de Política e Gestão da Educação, e do Programa de Pós-Graduação em Educação, Núcleo de Políticas Educacionais da UEL. E-mail: <fruiz@uel.br>Doutora em Educação pela Universidade Federal do Paraná, Mestre em Educação pela Universidade Federal Fluminense, Graduação em Pedagogia pela Universidade Estadual de Londrina. Professora Associada da Universidade Estadual de Londrina na área de Política e Gestão da Educação. E-mail: sandragarciapr@hotmail.com.

${ }^{4}$ Doutora em Educação pela Universidade Federal do Paraná, Mestre em Educação pela Universidade Federal Fluminense, Graduação em Pedagogia pela Universidade Estadual de Londrina. Professora Associada da Universidade Estadual de Londrina na área de Política e Gestão da Educação. E-mail: sandragarciapr@hotmail.com.
}

Trabalho \& Educação | v.28 | n.3 | p.87-100 | set-dez | 2019 
elaboration of the guidelines for the reform of the high school. It concludes by emphasizing that policies for education, historically, are elaborated in a context of dispute between projects very different from society and mediated by the confrontations between the antagonistic classes. Thus, they reinforce the offer of an education for the formation of the workforce that serves the interests of the entrepreneurs and moves away from the ideal of human formation and full of social subjects.

Keywords: Educational Policy. Public-Private. High school.

\section{INTRODUÇÃO}

Segundo Frigotto (2011), no campo de estudos das ciências humanas e sociais, qualquer objeto que vá tratar da historicidade dentro das contradições, mediações e determinações, deve levar em consideração a relação entre plano estrutural e conjuntural. Isso implica também, em tomar esse objeto como parte de uma totalidade histórica que o constituiu, estabelecendo mediações entre o campo da particularidade e sua relação com determinada universalidade. Sendo assim, tomaremos aqui as três últimas décadas dentro do cenário político brasileiro, que fundado nas políticas neoliberais, mostrou-se ora voltado a atender indistintamente a classe dominante, ora atendeu, mesmo que parcialmente os ensejos dos trabalhadores.

Partindo deste pressuposto, neste texto, defendemos a ideia de que reforma do Ensino Médio (EM) é mais uma na sucessão das políticas educacionais voltadas à formação para o mercado de trabalho. Como veremos, essa perspectiva foi reiterada na ditadura Vargas (Lei Capanema), Ditadura Civil-Militar (Lei no 5692/71), período FHC (LDBEN 9394/96) e no período Lula, pelo Projeto de Lei oㅡ 6840/2013, que serviu de base para a atual Lei no 13415/2017, sancionada pelo governo Temer. Para cada período houve um projeto para oferta da educação pública interligada aos interesses econômicos, uma formação específica para atender a demanda do mercado e o favorecimento dos empresários da educação.

No dia 23 de setembro de 2016, o governo federal divulgou a Medida Provisória 746, a MP do Ensino Médio. Nela, apresentou medidas para a reformulação desta etapa da educação básica, que se efetivaram na Lei o 13.415/20175. A reforma do Ensino Médio pode ser analisada em várias óticas, uma delas está ligada à reorganização dos orçamentos públicos ${ }^{6}$ em prol de interesses privados, que se colocam contra as políticas sociais. O presente texto, por meio de discussão bibliográfica e documental, tem dois objetivos: (i) apresentar os caminhos históricos que levaram o atual governo a sancionar a Lei no 13415/2017 da Reforma do Ensino Médio e (ii) discutir a tendência histórica da interferência dos empresários na elaboração das políticas educacionais, voltadas para o Ensino Médio e para a Educação Profissional no Brasil

Para atingir tais objetivos, o artigo segue organizado em duas seções. Na primeira discute as políticas educacionais implantadas desde a Lei Capanema, até a atual reforma do Ensino Médio, procurando elucidar as tendências históricas em ofertar um tipo de ensino interligado aos interesses do mercado. A seguir faz uma discussão sobre

\footnotetext{
${ }^{5}$ Tendo em vista que esta reforma ainda está em curso e em processo de ser implantada nas escolas, neste texto não temos a pretensão de analisá-la, mas apenas indicar que a mesma sofre a influência direta do empresariado da educação, no processo de sua formulação.

${ }^{6}$ Cabe destacar que parte do orçamento para a efetivação da reforma do EM foi adquirida via empréstimo do Governo Federal, no Banco Interamericano de desenvolvimento, o que reforça o caráter economicista desta Lei. "A implementação do Novo Ensino Médio nos Estados e Distrito Federal recebeu um reforço de peso [...] o Senado Federal autorizou um empréstimo de US\$250 milhões, junto ao Banco Internacional para Reconstrução e Desenvolvimento (Bird), o Banco Mundial, para apoiar a execução da reforma proposta pelo Ministério da Educação". http://portal.mec.gov.br/ultimas-noticias/211-218175739/63011-ministerio-contara-com-reforco-de-us-250milhoes-do-bird-para-implementacao-do-novo-ensino-medio
} 
as reformas educacionais no contexto neoliberal, a partir da Reforma do Estado, em 1995, evidenciando que os empresários da educação ganham, paulatinamente, o aval do Estado para interferir diretamente na elaboração das políticas educacionais.

\title{
Da Lei Capanema À Contrarreforma do Ensino Médio
}

Durante o Estado Novo, período em que o Brasil era comandado por Getúlio Vargas, o ministro da educação, Gustavo Capanema, apresentou a reforma que visava modificar a oferta da educação no país. Ao assumir o Ministério de Educação e Saúde em 1934, Capanema teve apoio de alguns intelectuais e contou com ajuda da Igreja Católica para desenvolver projetos e reformular o processo educacional. O governo recebeu o apoio da lgreja e em troca aprovou as chamadas emendas religiosas na Constituinte de 1934, que instituiu a obrigatoriedade do ensino religioso nas escolas públicas.

\begin{abstract}
Os argumentos priorizados no debate já não eram relativos apenas à organização curricular, mas à democratização e descentralização do ensino, tendo em vista as mudanças demográficas em curso, decorrentes da industrialização e urbanização, bem como os referentes à criação do sistema nacional de educação cuja organização e gestão caberiam ao Estado. Enquanto parte dos congressistas alinhou-se com as teses dos Pioneiros da Educação em defesa da escola pública e laica, bem como da democratização e descentralização, os afinados com as teses da Igreja e das escolas privadas defenderam a liberdade das famílias em escolher as escolas onde matricular seus filhos, tendo em vista, de um lado, o fortalecimento e ampliação da formação religiosa católica a maior número de adolescentes e jovens e, de outro, a manutenção do ensino privado que cedia espaço ao ensino público. Por isso, rejeitavam a proposta de seus oponentes. (FERRETTI, 2016, p. 75).
\end{abstract}

A disputa naquele período se dava entre os defensores da escola pública, gratuita e laica de um lado, e de outro, a lgreja, defendendo o ensino privado, como espaço garantidor do ensino confessional. Prevaleceu os interesses da lgreja, e junto, o projeto para colocar em prática nas escolas públicas a formação tecnicista. Da fusão EstadoIgreja resultou um ensino com ênfase dada ao ensino humanista na escola secundária destinada à pequena parcela da classe dominante. Para a classe trabalhadora seria destinada o ensino primário e escolas profissionalizantes ligadas ao comércio, indústria e agricultura. Houve a criação do "Sistema S"7, agregando o Serviço Nacional de Aprendizagem Industrial (SENAI) e Serviço Nacional de Aprendizagem do Comércio (SENAC). Este sistema, forte aliado do empresariado, organiza-se para ofertar a qualificação para o trabalho. Neste período, as Leis Orgânicas foram estruturadas da seguinte forma:

Quatro decretos são editados durante o Estado Novo: a) Decreto-lei 4.073, em 30 de janeiro de 1942 (Lei Orgânica do Ensino Industrial); b) Decreto-lei 4.048, em 22 de janeiro de 1942, cria o Serviço Nacional de Aprendizagem Industrial (SENAI), c) Decreto-lei 4.244, em 9 de abril de 1942 (Lei Orgânica do Ensino Secundário) e d) Decreto-lei 6.141, em 28 de dezembro de 1943 (Lei Orgânica do Ensino Comercial). Após o golpe militar que derrubou Vargas (1945), durante o Governo Provisório presidido pelo Presidente do Supremo Tribunal Federal (STF), foram publicados mais quatro decretos-lei: a) Decreto-lei 8.529, em 02 de janeiro de 1946 (Lei Orgânica do Ensino Primário); b) Decreto-lei 8.530, em 02 de janeiro de 1946 (Lei Orgânica do Ensino Normal); c) Decreto-lei 8.621 e 8.622,

\footnotetext{
${ }^{7}$ Sistema S de educação é composto por: Serviço Nacional de Aprendizagem Industrial (Senai); Senviço Social do Comércio (Sesc); Serviço Social da Indústria (Sesi); e Serviço Nacional de Aprendizagem do Comércio (Senac). Existem ainda os seguintes: Senviço Nacional de Aprendizagem Rural (Senar); Serviço Nacional de Aprendizagem do Cooperativismo (Sescoop); e Serviço Social de Transporte (Sest).
} 
em 10 de janeiro de 1946, criam o Serviço Nacional de Aprendizagem Comercial (SENAC) e d) Decreto-lei 9.613, em 20 de agosto de 1946 (Lei Orgânica do Ensino Agrícola). (PALMA FILHO, 2005, p.11)

As Leis Orgânicas promulgadas por Decreto-Lei (Medida Provisória) foram consideradas parciais por não abranger todo o ensino, pois eram destinadas a um ramo de ensino separado e isolado, tendo a intenção de favorecer grupos políticos e empresários. Com a redefinição do currículo, o ensino secundário ganhou cunho propedêutico e profissional. Sendo o propedêutico destinado à formação dos dirigentes e, portanto, ofertado à classe dominante. E o ensino profissional voltado a atender as necessidades de formação de mão de obra, esse ofertado à classe trabalhadora. Para o ensino profissional foram designados os setores da produção: primário, para o ensino agrícola; secundário para o ensino industrial; terciário para o ensino comercial e o ensino normal para a formação de professores.

Segundo Palma Filho (2005, p. 12), "o ensino secundário ficava estruturado em dois níveis: ginásio, com a duração de quatro anos, ao qual se seguia o colégio com a duração de três anos. Este, não mais subdividido em três ramos, mas sim, em dois (científico e clássico)." A diferença se dava na ênfase de cada estrutura, o científico aprofundava nas questões de Ciências Naturais, enquanto que o clássico dava maior atenção às humanidades. Os formuladores das políticas educacionais da época entendiam que assim se atenuava a preparação para o vestibular.

\begin{abstract}
A estruturação definitiva dos cursos técnicos profissionalizantes, destinados às camadas populares, é mérito indiscutível da reforma educacional empreendida pelo Ministro Gustavo Capanema, como, aliás, vimos estava estabelecido pela Carta Constitucional outorgada por Getúlio Vargas, em 1937. O ginásio e colégio secundários às "elites condutoras"; o ensino técnico-profissionalizante, "às massas a serem conduzidas". Tudo certinho, só faltou combinar com o povo que continuou sem escola na sua grande maioria, e os que conseguiam furar o bloqueio do exame de admissão ao ginásio, evidentemente, preferiam o curso secundário, pois apenas esse dava acesso ao curso superior. Este aspecto da legislação educacional dos "tempos Capanema" é, aliás, altamente discriminatório em relação às camadas populares e consagrava o já conhecido "dualismo" do sistema educacional brasileiro, muito bem caracterizado por Anísio Teixeira na feliz expressão: "de um lado a escola para os nossos filhos, de outro, a escola para os filhos dos outros" (PALMA FILHO, 2005, p.13 Grifos do autor).
\end{abstract}

De acordo com Ferretti (2016), ocorreu uma tensão entre os defensores da formação clássica e a científica, sendo a formação científica a mais valorizada. Essa disputa marcou o ensino secundário e desembocou na promulgação da LDB № 4024 de 1961. Com isso, ao $1^{\circ}$ e $2^{\circ}$ ciclo foi atenuado à flexibilização curricular decorrente da possibilidade de ofertas de disciplinas obrigatórias, optativas e complementares. $O$ processo de democratização da oferta de ensino era a grande preocupação de alguns intelectuais da época. No entanto, ao inserir jovens oriundos de setores médios e populares (classe trabalhadora), contribuía para a crítica referente à formação clássica e também aos procedimentos pedagógicos das escolas frequentadas por sujeitos oriundos da antiga aristocracia, ou seja, da classe dominante. A concepção e a metodologia de ensino deveriam ser revistas, pois a concepção de ensino não se adequava à industrialização do país, e a metodologia não se mostrava adequada a sujeitos sociais da classe trabalhadora, cuja inserção social seria diferente ao que era proposto na educação clássica. Nesta perspectiva, a classe trabalhadora não precisava, segundo o ideário da classe dominante, receber uma educação voltada para 
formação científica. Para esta deveria ser destinada a profissionalização para formação da força de trabalho, a ser utilizada pelo capital.

Segundo Ferreira (2017) a edição da LDB o 4.024/61 deu o reconhecimento à integração entre o ensino profissional e o ensino regular de segundo ciclo para fins de prosseguimento de estudos. A expansão escolar no período da Ditadura Civil-Militar não foi fruto de um único conjunto de interesses, no caso do setor público, mas sim, houve outros setores interessados na expansão escolar, como o setor privado que queria se beneficiar de subsídios do Estado.

A institucionalização do ensino profissionalizante teve suas bases em Leis promulgadas no período ditatorial. De acordo com Ferreira e Bittar (2008) as Leis no 5.540/68 e no 5.692/71 são frutos da necessidade produtiva vivenciada pelo país como: a formação da força de trabalho e do desenvolvimento produtivo e tecnocrático do sistema capitalista implantado no país: "foram reformas educacionais que estavam inseridas num contexto histórico de transição de uma sociedade agrária para uma sociedade urbano-industrial, cujas transformações societárias se desenrolavam desde 1930" (FERREIRA; BITTAR, 2008, p. 336).

Com a Lei $n^{\circ} 5692 / 71$ os antigos cursos primários e, também, de ciclo ginasial foram agrupados no ensino de $1^{\circ}$ grau, ampliando, assim, para oito anos o ensino obrigatório. Segundo Ghiraldelli Jr. (2001, p.182), o ensino era destinado à formação dos alunos em conteúdos e métodos, conforme as fases de desenvolvimento dos mesmos. $\mathrm{O}$ Conselho Federal de Educação fixou as matérias de núcleo comum para o ensino de $1^{\circ}$ e $2^{\circ}$ grau, obrigatório, e ainda, com uma parte diversificada para compreender as necessidades e as peculiaridades locais de cada região do país. Entretanto, $02^{\circ}$ grau tornou-se, integralmente profissionalizante, pois, de acordo com Ghiraldelli Jr. (2001, p. 182):

[...] o elenco de habilitações chegou efetivamente ao impraticável. As escolas poderiam montar um $2^{\circ}$ grau com habilitações em "Carne e Derivados", ou em "Cervejaria e refrigerantes", ou em "Leite e Derivados". É obvio que os colégios particulares (e os grandes empresários do ensino sempre tiveram grande influência no interior do CFE) souberam desconsiderar toda essa parafernália "profissionalizante". As escolas particulares, preocupadas em satisfazer os interesses de sua clientela, ou seja, em propiciar o acesso ao $3^{\circ}$ grau, desconsideraram (através de fraude, obviamente) tais habilitações e continuaram a oferecer o curso colegial propedêutico à universidade. As escolas públicas, obrigadas a cumprir a lei, foram desastrosamente descaracterizadas.

O ensino profissionalizante compulsório foi um fracasso em termos do que entendemos como educação emancipatória, mas serviu de apoio aos interesses privatizantes e a lógica de mercado que buscou na escola pública a formação profissional que serviu de base para a industrialização do país. Na década de 1980 houve grandes mobilizações para a democratização da educação, tendo em vista o findar da ditadura civil-militar. Contudo, este processo político foi atravessado pela "onda neoliberal" (LAVAL, 2004) que já havia se estabelecido em países de capitalismo avançado e chegava ao Brasil na década de 1990, mais especificamente em 1995, assolando a breve conquista dos direitos sociais, garantidos na CF de 1988. Isso implicará na reiteração da dualidade 
estrutural $^{8}$ que marca a educação do estudante do ensino médio e profissional, historicamente, como veremos a seguir.

\section{A REFORMA DA EDUCAÇÃO NO CONTEXTO NEOLIBERAL}

Em 1996 após intenso e conflituoso processo de oito anos a LDB 9394/96 foi aprovada. Ferretti (2016) afirma que o primeiro Projeto de Lei da LDB, na década de 1990, foi apresentado por entidades da sociedade civil. Naquela proposta, havia a preocupação em formular um ensino médio que tivesse por base a concepção da educação politécnica e da escola unitária defendidas por Marx e Engels (1983) e Gramsci (1979).

No entanto, a aprovação da LDBEN no 9394/96, pelo presidente FHC, ocorre em um processo de disputa entre diferentes projetos societários. Isso resulta em uma LDBEN bastante flexível, o que aparece de forma mais concreta no capítulo da Educação Profissional, que segundo Saviani (1997, p. 9), "parece mais uma carta de intenções do que um documento legal, já que não define instâncias, competências e responsabilidades". O intuito foi de esvaziamento desta LDBEN nas questões referentes ao Ensino Médio e da Educação Profissional, porque este tema já estava sendo tratado paralelamente pelo PL no 1603/96, que separava totalmente o Ensino Médio da Educação Profissional, seguindo itinerários próprios.

Em 1997 o Decreto 2.208 reitera a separação entre ensino médio e ensino técnico, uma medida que foi tomada para que houvesse um ajustamento da educação brasileira aos interesses internacionais, interesses que visam à manutenção do sistema capitalista, tendo a escola a base para sua efetivação. Sobre isso Ferretti comenta que

Tal medida buscou ajustar a educação nacional aos discursos e práticas internacionais relativamente à necessidade da educação rever-se tendo em função dos interesses desencadeados pelas transformações em curso no âmbito do trabalho a partir da década de 1970 - a denominada reestruturação produtiva. Criaram-se, por essa forma, as condições para a instituição de um projeto educacional voltado para a formação dos sujeitos sociais adequados às formas flexíveis de organização do trabalho, não só como produtores, mas, também, como consumidores. Tal projeto materializou-se, como tal, em documentos legais tais como a LDB 9.394/96 e, mais especificamente, no que diz respeito à última etapa da Educação Básica, nas Diretrizes Curriculares Nacionais para o Ensino Médio, de 1998, bem como nas Diretrizes Curriculares Nacionais para a Educação Profissional Técnica de Nível Médio, de 1999 (FERRETTI, 2016, p.81).

Ainda, de acordo com Ferretti (2016), as medidas adotadas durante o governo de FHC enfrentaram dois problemas: a dificuldade em se materializar nas escolas, mesmo o MEC ofertando formação continuada, produção curricular e a distribuição de material didático; houve a resistência por parte dos professores.

A separação do Ensino Médio da Educação Profissional trouxe graves consequências na formação da juventude brasileira, pois houve tanto um esvaziamento da formação nos cursos denominados de "regular" ou propedêutico, como dos cursos profissionalizantes. É preciso ressaltar que o objetivo principal da reforma dos anos

\footnotetext{
${ }^{8}$ O conceito de dualidade estrutural está fundado na teoria da escola dualista de Baudelot e Establet (1971 apud SAVIANI, 2007a) que desconstrói a ideia de que a escola não é unitária e nem unificadora, mas se divide em duas, sendo uma voltada para a educação dos filhos dos trabalhadores e a outra voltada para a burguesia. Essa dualidade estrutural tem estado presente em toda a história da educação brasileira. Disponível

https:/www.researchgate.net/publication/285072602 Dualidade estrutural no ensino tecnico profissionalizante em Brasilia IFB uma analise do discurso oficial de inclusao e as dificuldades de permanencia dos alunos. Acesso em: 10 dez. 2019.
} 
1990 era de que as Instituições Federais, o antigo Centro Federal de Educação Tecnológica (CEFET), cumprissem o objetivo de formar diretamente para o mercado e não para que os estudantes continuassem seus estudos. De acordo com o Ministro da Educação a época, Paulo Renato, estes objetivos não estavam sendo atingidos. Houve no início uma certa resistência em implantar a reforma, no entanto ocorreu um processo de acomodação tanto da rede federal como das estaduais com a destinação de recursos advindos dos empréstimos internacionais. Movimento análogo ocorre em tempos atuais, quando novamente as Instituições Financeiras internacionais aparecerem como financiadoras da atual reforma pela Lei no13415/17.

No primeiro mandato do Presidente Luis Inácio Lula da Silva, 2003, alguns educadores questionavam as medidas tomadas por FHC. Houve mobilizações e vários debates em seminários nacionais voltados a professores e gestores do ensino médio e do ensino técnico. E da Educação Profissional. A finalidade era de retomar os princípios que estavam nas primeiras versões da LDBEN, ou seja, trazer a discussão da educação politécnica e omnilateral, da formação humana integral e formar um sistema educacional sólido no país. Apesar dos esforços dos profissionais da educação, o embate político do período impediu a total revogação do Decreto 2.208/1997.

Os seminários nacionais voltados a professores e gestores do Ensino Médio e do Ensino Técnico, realizados pela então Secretaria do Ensino Médio e do Ensino Técnico (SEMTEC) do MEC em 2003, e a proposição e posterior aprovação do Decreto 5.154/2004 representam movimentos nesse sentido. No entanto, conforme apontam Frigotto, Ciavatta e Ramos (2005) o referido decreto foi marcado pelos embates políticos da época o que impediu a completa revogação do Decreto 2.208/1997, como era a intenção inicial que se voltava predominantemente para o ensino médio integrado, razão pela qual foram mantidas, além dessa forma, a subsequente e a concomitante de articulação entre o ensino médio e a educação profissional de nível técnico, incorporadas posteriormente à LDB. Além disso, a ação do Conselho Nacional de Educação ao invés de elaborar novas Diretrizes Curriculares Nacionais do Ensino Técnico apenas atualizou as promulgadas em 1998 e 1999, mantendo seu espírito (FERRETTI, 2016, p. 82).

Num processo de acomodação e não de ruptura foi elaborado e aprovado o Decreto $5.154 / 2004$, impulsionado por grupos de educadores afinados com os fundamentos teóricos e políticos de uma educação emancipadora. A não ruptura do modelo de formação para a juventude brasileira, nos parece ter sido um dos erros graves no início da gestão de Lula e deu espaço para a atual reforma, como veremos a frente.

A principal mudança assegurada pelo Decreto n. 5154/04 foi a retomada da possibilidade do Ensino Médio integrado com a Educação Profissional, que tinha como princípio, mesmo num processo de contradição, possibilitar a integração curricular retomando o trabalho, a ciência a cultura e a tecnologia como meio fundante para a formação humana integral. Em 2008 através do PL no11741 a LDB é alterada com o teor do decreto $\mathrm{n}^{\circ}$ 5154/04, este perdendo a validade.

Do resultado deste processo de discussão é elaborado pelo MEC o Documento Base sobre o Ensino Médio Integrado a Educação Profissional, que foi o documento orientador da elaboração das Diretrizes Curriculares Nacionais do Ensino Médio e também das Diretrizes Curriculares Nacionais da Educação Profissional e de outros programas elaborados pelo MEC, no período de 2003 ao primeiro semestre de 2016. É preciso registrar que foi um documento orientador, no entanto programas e ou políticas foram elaborados neste período com grandes contradições, como por exemplo, o Programa Nacional de Acesso ao Ensino Técnico e Emprego (PRONATEC). 
Um grupo focou na produção de texto do Documento Base sobre a Educação Profissional, em 2007, e também do Programa Ensino Médio Inovador (PROEMl 2009), os quais sugeriram fundamentações teóricas e instruções práticas para sua implementação. Também foram realizados encontros e seminários com a finalidade de submeter à Câmara de Educação Básica do Conselho Nacional de Educação (CNE) as proposições para mudança nas Diretrizes Curriculares para que o Ensino Médio e a Educação Profissional Técnica de Nível Médio se adequassem aos fundamentos da formação unitária de caráter politécnico e omnilateral.

\begin{abstract}
Tais movimentos se deram simultaneamente a ações governamentais que resultaram na proposição do PDE e na constituição da Rede Federal de Educação Profissional. A instituição mais preeminente dessa rede é o Instituto Federal de Educação, Ciência e Tecnologia (IF), a que foi atribuída específica, mas não exclusivamente, a implementação da Educação Profissional Técnica integrada ao Ensino Médio sob a forma dos cursos técnicos integrados. Ainda que houvesse a compreensão de que a proposição de mudanças nas diretrizes curriculares seria, por si só, insuficiente para viabilizar a formação unitária, considerou-se que serviria de referência para sua concretização, contribuindo, além disso, para evitar algumas distorções que vinham sendo observadas a respeito dessa concepção (FERRETTI, 2016, p. 82).
\end{abstract}

Num outro processo de contradição em 2005 é aprovada a Lei no 11.096 que institui $O$ Programa Universidade para Todos (PROUNI), abrindo para a possibilidade de privatização do Ensino Superior. Ao contrário dos educadores que buscavam colocar em prática a educação unitária, o empresariado foi fortemente representado pelo projeto de lei enviado à Câmara dos Deputados, em 2004, que adaptou os termos aos interesses do setor privado. Tal feito resultou na Lei n. 11.096, de 13 de janeiro de 2005. Esta Lei reconheceu que "a instituição privada de ensino superior, com fins lucrativos ou sem fins lucrativos não beneficente, poderá aderir ao Prouni, mediante assinatura de termo de adesão" (BRASIL, 2005).

Constata-se que, desta forma, continua a possibilidade de destinação dos recursos públicos para o setor privado. Dentro dessa lógica, em 2006, alguns grupos empresariais se agregaram em um movimento com o slogan "Todos Pela Educação9", que conta com uma gama de aproximadamente 32 organizações sociais (OSs), presidida, na época, por Jorge Gerdau. Tal grupo teve forte interferência na elaboração do Plano de Desenvolvimento da Educação (PDE-2007), sendo que, o Decreto presidencial de 2007 que dispõe sobre a implementação deste Plano, acaba sendo intitulado com nome análogo ao do movimento empresarial, a saber: "Plano de Metas Compromisso Todos pela Educação". Ou seja, aparentemente, a escolha do nome do Decreto pode de certa forma indicar uma espécie de homenagem a este movimento empresarial (SAVIANI, 2007).

Para a adesão do Plano de Metas Compromisso Todos Pela Educação, no Decreto no 6.094/2007 em seu Art. 7, consta quem poderá colaborar para a oferta da educação pública:

Art. $7^{\circ}$ Podem colaborar com o Compromisso, em caráter voluntário, outros entes, públicos e privados, tais como organizações sindicais e da sociedade civil, fundações, entidades de classe empresariais, igrejas e entidades confessionais, famílias, pessoas físicas e

\footnotetext{
9 "Movimento lançado em 6 de setembro de 2006 no Museu do Ipiranga, em São Paulo. Apresentando-se como uma iniciativa da sociedade civil e conclamando a participação de todos os setores sociais, esse movimento se constituiu, de fato, como um aglomerado de grupos empresariais (SAVIANI, 2007, p. 1243).
} 
jurídicas que se mobilizem para a melhoria da qualidade da educação básica. (BRASIL, 2007-grifo nosso).

Segue assim medidas que possibilitam que os recursos públicos sejam desviados para o setor privado. Dessa forma, a escola perde seu caráter público e fica suscetível a processos de privatização, atualmente mais representado pela publicização ou descentralizaçãa ${ }^{10}$, sendo estas diferentes formas de privatização cunhadas pelo neoliberalismo. Somado a isso, a formação dos alunos continua a critério e a fim de atender as necessidades do mercado de trabalho.

De acordo com Frigotto (2011), esse movimento, contrasta com a história de resistência das entidades que lutam por uma educação pública e gratuita e revela o caráter cínico e a disputa pela hegemonia do pensamento educacional mercantil nas escolas públicas. Este mesmo autor, em outro texto, destaca que

Não por acaso, o Movimento Escola "sem" Partido começou em 2004 e o Todos pela Educação, em 2005 - ainda que oficializado em 2006, demonstrou sua força com a deflagração do Plano de Desenvolvimento da Educação decretado pelo MEC com o nome Compromisso Todos pela Educação (Decreto n 6.094/2007). Também colocamos "sem" partido entre aspas, pois, na verdade, trata-se do partido único do capital, do mercado e do ódio ao pensamento crítico. (FRIGOTTO, 2017, s.p.)

No que diz respeito à Educação Profissional, a parceria entre o setor público e o movimento empresarial pode ser percebida também no Programa Nacional de Acesso ao Ensino Técnico e Emprego (PRONATEC), promulgado pela Lei oํ 12.513/2011. Este foi um dos meios pelo qual o Sistema $S$ de educação coopta recursos públicos, o que é notório nos dizeres de Motta e Frigotto (2017).

\begin{abstract}
Em levantamento realizado em julho de 2015 (não publicado), constatamos que a União transferiu recursos para o programa, em 2014, no montante de $R \$ 2.648 .668 .385,35$, sendo que $\mathrm{R} \$ 2.581 .208 .152,00$ foram destinados ao Sistema S. Até junho de 2015, em meio aos cortes na educação, tinham sido transferidos para o Pronatec $R \$ 551.413 .899,65$ e, desse montante, $R \$ 518.393 .229,20$ foram destinados ao Sistema $S 4$. Além da quase totalidade dos recursos públicos voltados para o "Ensino Técnico e ao emprego" - parte da sigla do programa - ter sido destinada ao setor privado, os cursos ofertados foram focados na FIC, isto é, em cursos de curta duração e voltados para o trabalho simples ofertados pelo Sistema S (MOTTA; FRIGOTTO, 2017, p. 361).
\end{abstract}

Outro movimento ocorre quando e formada a Comissão Especial de Educação da Câmara Federal que apresentou, em 2013, o Projeto de Lei no 6840 que, apesar da realização de audiências públicas nos estados e no próprio Congresso Nacional, teve como principais interlocutores, o grupo integrante do Movimento Todos pela Educação, portanto, instituições ligadas ao grande empresariado. Em 2014 o Movimento Nacional em Defesa do Ensino Médio (MNDEM), criado a partir deste debate, consegue um canal de interlocução com o presidente da Comissão e consegue uma mudança substancial que é apresentada em 2014. O texto apresentado na sua segunda versão, após a participação do MNDEM, amenizou formulações que poderiam causar polêmicas e o teor das propostas e incorporou elementos das Diretrizes Curriculares Nacionais do Ensino Médio que foram aprovadas em 2011, porém, não retirou de pauta a escolarização em tempo integral e a formação de caráter específica e

\footnotetext{
${ }^{10}$ Compreende a "descentralização para o setor público não-estatal da execução de senviços que não envolvem o exercício do poder de Estado, mas devem ser subsidiados pelo Estado, como é o caso dos serviços de educação, saúde, cultura e pesquisa cientíica". (BRASIL, 1995, p. 12-13).
} 
imediatista por área de conhecimentos ou itinerários formativos. O que se tinha em vista, naquele momento, e que acabou por concretizar na reforma atual do Ensino Médio, é o encaminhamento para cursos superiores, dando assim, contribuições para as instituições de ensino superior privadas.

Para Motta e Frigotto (2017), a urgência em que foi aprovada a reforma do Ensino Médio, segundo os dirigentes do Ministério da Educação (MEC) é referente à necessidade em destravar as barreiras que impedem o crescimento econômico. Assim, a educação mais uma vez figura como a propulsora para a retomada do crescimento econômico, ideia inspirada na questão de que o investimento no capital humano potencializa a produtividade e ajuda a elevar as condições de competitividade do Brasil, no mercado internacional. Como afirmam Motta e Frigotto (2017, p. 358) "Sintetizando, as questões-chave da MP no 746/2016 (Lei no 13.415/2017) são: investir no capital humano visando maior produtividade; modernizar a estrutura curricular, flexibilizando por áreas de conhecimento; e melhorar os resultados do desempenho escolar."

É preciso ressaltar que a Lei n. 13.415/2017 foi posta em discussão de forma aligeirada e descartou totalmente as manifestações das entidades e profissionais da área da educação. Isso prova que o governo tem usado estratégias para colocar em prática uma formação precária que visa atender aos interesses do empresariado. Muitos educadores e pesquisadores têm se referido a atual reforma com a terminologia "contrarreforma", ou seja, o que apresenta como um meio de melhoria para a etapa final da educação básica, nada mais é que um meio de ir contra uma real reforma que esta etapa de ensino necessita, que incorpore e oferte uma formação integral e omnilateral.

Ao que tudo indica, há uma necessidade em capacitar o alunado para determinadas áreas do saber que o mercado de trabalho tem exigido. Tem sido divulgada a ideia da inutilidade de algumas disciplinas, estas mais referentes a área de humanas, como caso de filosofia, sociologia e história. Sobre isso, Luiz Eduardo Leão11, gerente do SENAl, comenta que as escolas brasileiras estão com ensino conteudista e centrada na transmissão de teorias, ficando sem conexão com a prática e habilidades socioemocionais que o mercado de trabalho exige, e isto desestimula o alunado a seguir nos estudos.

A flexibilização do currículo, a "livre iniciativa" do aluno em escolher as disciplinas em obrigatórias e optativas remetendo a Leis Orgânicas da Reforma Capanema, já supracitada, atende a tipos específicos de ensino. Assim, a dualidade em ofertar ensino clássico e científico é resgatada deixando a escola pública que atende a classe trabalhadora mais uma vez a serviço do mercado.

A reforma do ensino médio vai ser posta em prática alinhada à aprovação da Base Nacional Comum Curricular do Ensino Médio (BNCC), que já foi aprovada e encontrase em fase de implementação dos Estados e Município e será o alicerce da reforma. Uma Base construída por um grupo de "notáveis intelectuais" que teve a centralidade nas disciplinas de português e matemática, deixando em segundo plano os outros componentes curriculares. Uma Base que define que $60 \%$ dos conteúdos do currículo da escola deve ser cumprido a partir do que ela indica o que será o referencial para as avaliações externas, ficando o sistema de ensino e a escola com apenas $40 \%$ de parte diversificada.

\footnotetext{
${ }^{11}$ https://exame.abril.com.br/carreira/estas-sao-as-competencias-mais-procuradas-no-brasil-de-2017/
} 
Neste momento a BNCC do Ensino Médio vem sendo discutida em audiências públicas pelo Conselho Nacional de Educação, no entanto como o resultado das audiências, na sua maioria tem sido contra a BNCC e contra a reforma. O MEC, por sua vez, anunciou recentemente o dia "D" para as escolas discutirem e, por meio do site governamental, enviarem suas contribuições, o que nos parece ser uma artimanha para tentar legitimar uma proposta que vem sendo veementemente rechaçada pelos educadores brasileiros.

Um dos objetivos do Grupo de Trabalho (GT) o Conselho Nacional de Secretários de Educação (CONSED), para 2017, foi o desenvolvimento de uma proposta para a BNCC e a flexibilização do currículo para o EM. Além disso, o CONSED está promovendo, estrategicamente, debates para a ampliação do tempo integral. Fundado em 1986, o CONSED é uma associação de direito privado, sem fins lucrativos e é composto por Secretarias de Educação dos Estados e do Distrito Federal. É um órgão de pessoa jurídica que atua nas instituições públicas. Apresenta-se com a finalidade de integrar as Secretarias de Educação dos estados brasileiros para a oferta da educação pública, atua principalmente na elaboração, formulação, implementação e avaliação de políticas educacionais, articulando os interesses das instâncias do governo com a sociedade civil. Explicitando melhor: a Reforma do Ensino Médio necessita da BNCC para garantir a flexibilização do currículo aprovada pela Reforma, que parte das metas do PNE, que por sua vez vai atender os interesses do Compromisso Todos Pela Educação, tudo isso articulado pelo CONSED, como representado no esquema a seguir:

Figura 1: Articulações do CONSED

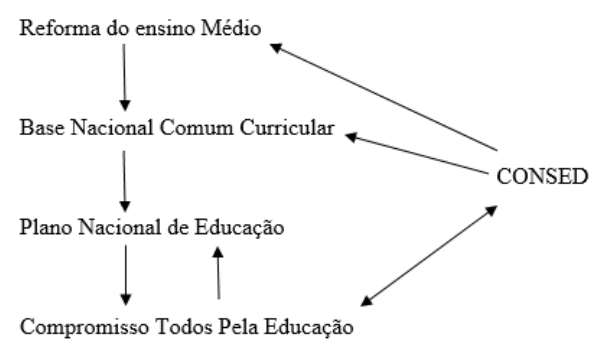

Fonte: elaborado pelas autoras

No ano de 2011, o CONSED teve como bandeira a aprovação do Plano Nacional de Educação (PNE). A entidade ficou encarregada de acompanhar a tramitação da lei no Congresso e nas comissões do Senado e da Câmara dos Deputados. Buscavam em 2012, fortalecer as parcerias principalmente no debate da discussão das dificuldades que os estados enfrentavam em relação a esta etapa da Educação Básica. $O$ CONSED foi o propulsor da entrada nas Secretarias Estaduais de Educação de Programas como o Jovem de Futuro do Instituto Unibanco e as Escolas de tempo Integral do Instituto de Corresponsabilidade em Educação, para a elaboração das diretrizes do Ensino Médio. Contudo, é preciso cautela para tentar entender a elaboração dos vários processos de disputa por quais passaram a BNCC, tema este aberto para pesquisas futuras.

Embora, notadamente, o movimento Todos Pela Educação seja um conglomerado de grandes empresas privadas que visam transformar a oferta da educação pública em um mercado, o CONSED tem sido responsável por debater as necessidades da Reforma do Ensino Médio, articulando um currículo flexibilizado para a BNCC. Porém, 
quem tem feito os debates com a associação são os empresários da educação. Assim, empresas privadas têm firmado parceria com o CONSED desde que este foi designado a abrir diálogo com a sociedade civil. Conforme ilustrado na figura a seguir:

Figura 2: Parcerias firmadas para a Reforma do Ensino Médio (CONSED - Todos Pela Educação):

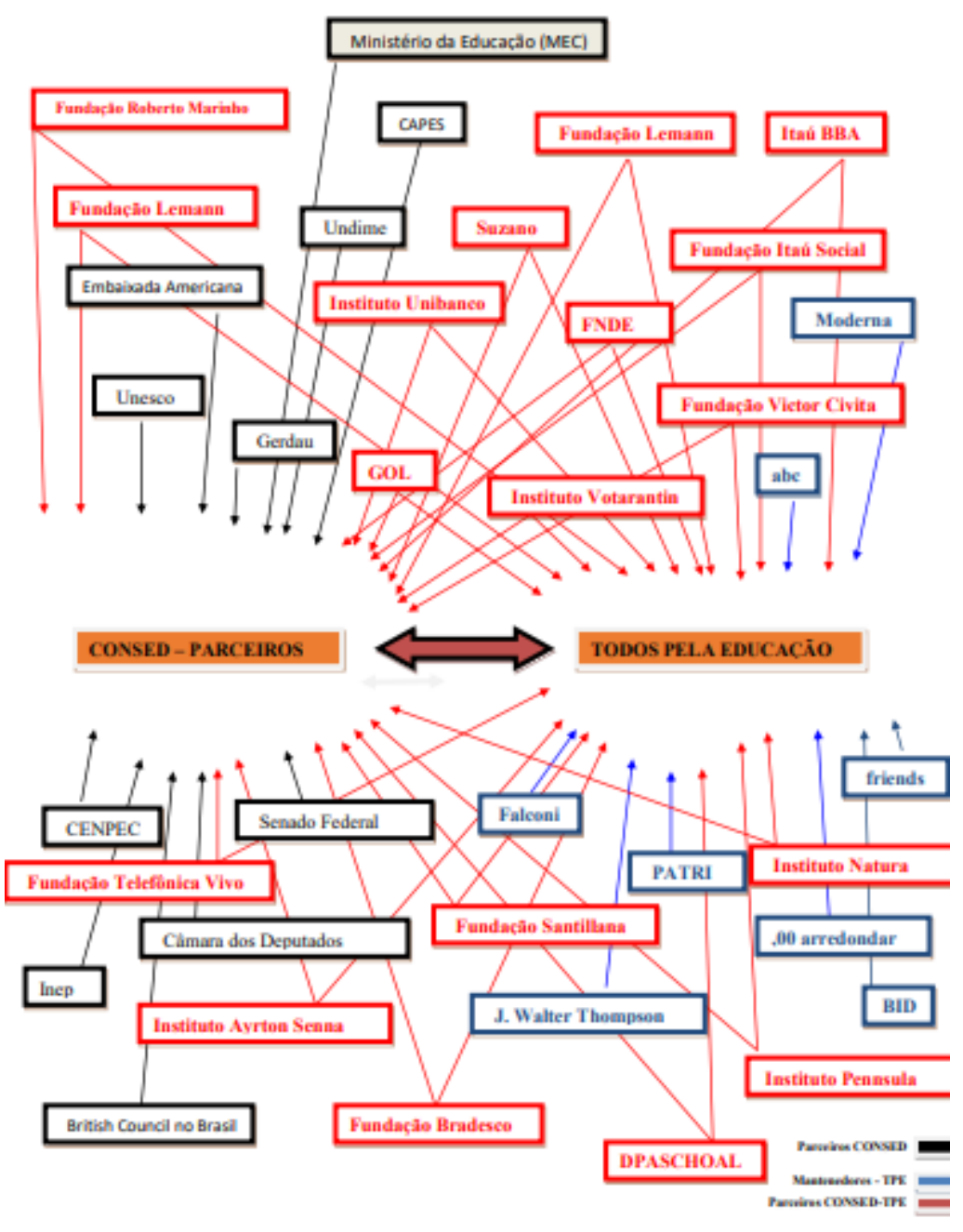

Fonte: elaborado pelas autoras.

A figura acima mostra quem são os parceiros do CONSED, nota-se que não há nenhuma entidade educacional que agrega professores e pesquisadores da área da educação - Fórum Nacional de Educação (FNE), ANFOPE, ANPAE, ANPED, CEDES, FORUMDIR, APEOESP, movimentos sociais estudantis, entre outras - ou seja, entidades que defendem a educação pública e gratuita. Além disso, como corrobora Frigotto (2011, p. 245), o movimento empresarial Todos Pela Educação, como já supracitado neste artigo, um dos principais parceiros e articuladores do CONSED, tem 
características dúbias e tentam "disputar a hegemonia do pensamento educacional", tornando a escola pública um mercado. Isso "contrasta com a resistência histórica" dos intelectuais que defendem a educação pública, gratuita, universal, laica e unitária, que prime pelo desenvolvimento geral e humanístico voltado para a formação integral e não apenas para a atuação no mercado de trabalho.

\section{CONSIDERAÇÕES FINAIS}

A educação ofertada por meio da escola pública, por décadas atende a interesses específicos dos detentores do poder ligados a grupos empresariais. Tais grupos não desejam ofertar uma educação que vise à formação completa do sujeito, pelo contrário, devido à busca de acumulação de capital por essa pequena parcela, a educação ofertada é sempre interligada aos interesses do mercado, ou seja, forma o sujeito para que esse se encaixe aos modos de produção capitalista. $O$ atual desejo imediatista é apenas mais uma contribuição para as demandas que interessam a economia capitalista, pois as reformulações de conteúdo e currículo estão interligadas a questões de financiamentos e aos interesses dos empresários da educação. Com isso, os itinerários terão dois pontos específicos: o primeiro é em atender a comércio e indústrias locais; e o segundo em adaptar a classe trabalhadora ao meio precário no qual já está imersa.

Assim, concluímos destacando que as políticas para a educação, historicamente, são elaboradas em um contexto de disputa entre projetos muito diferentes de sociedade e mediatizadas pelos confrontos entre as classes antagônicas. Neste jogo de forças políticas, no mais das vezes, estas políticas reforçam a oferta de uma educação para formação de mão de obra atendendo aos interesses do empresariado e se afastando do ideal da formação humana e plena dos sujeitos sociais. Contudo, o que aqui se apresenta de forma bastante econômica devido ao espaço deste texto, precisa ser acompanhado de perto por pesquisas acadêmicas futuras a fim de delinear de forma mais específica o curso histórico das políticas educacionais para a formação dos trabalhadores.

\section{REFERÊNCIAS}

BRASIL, Decreto № 6.094, de 24 de Abril de 2007. Disponível em: http://www.planalto.gov.br/ccivil 03/ ato2007-2010/2007/decreto/d6094.htm Acesso em: 09 jul. 2018.

BRASIL. Plano Diretor da Reforma do Aparelho do Estado. Brasília, 1995. Disponível em: http://www.biblioteca.presidencia.gov.br/publicacoes-oficiais/catalogo/fhc/plano-diretor-da-reforma-doaparelho-do-estado-1995.pdf Acesso em :11 jul. 2018.

BRASIL. Lei n. 13.415/2017. Altera as Leis no 9.394, de 20 de dezembro de 1996, que estabelece as diretrizes e [...] e institui a Política de Fomento à Implementação de Escolas de Ensino Médio em Tempo Integral. Disponível em: http://www2.camara.leg.br/legin/fed/lei/2017/lei-13415-16-fevereiro-2017-784336publicacaooriginal-152003-pl.html. Acesso em: 12 jul. 2018.

FERRETTI, Celso J. Reformulações do Ensino Médio. Revista HOLOS, Ano 32, Vol. 6. 2016

FERREIRA, Eliza B. A Contrarreforma do ensino Médio no Contexto da Nova Ordem e Progresso. Educ. Soc., Campinas, v. 38, no. 139, p.293-308, abr.-jun., 2017

FERREIRA, Amarilio; BITTAR, Marisa. Educação e ideologia tecnocrática na Ditadura Militar. Cad. Cedes, Campinas, Vol. 28, n. 76, p. 333-355, 2008. 
FRIGOTTO, Gaudêncio. Os Circuitos da História e o balanço da educação no Brasil na primeira década do Século XXI. In: Revista Brasileira de Educação. V. 16, n. 46, 2011. p. 235-254. Disponível em: http://www.scielo.br/pdf/rbedu/v16n46/v16n46a13. Acesso em:12 jul. 2018.

GHIRALDELLI JR., Paulo. História da Educação. 2ª . Ed. São Paulo, SP: Cortez, 2001.

LAVAL, C. A escola não é uma empresa: o neo-liberalismo em ataque ao ensino público. Londrina: Planta, 2004.

MOTTA, Vânia Cardoso da.; FRIGOTTO, Gaudêncio. Porque a urgência da Reforma do Ensino Médio? Medida Provisória N. 746/2016 (Lei n. 13.415/2017). Educ. Soc., Campinas, v. 38, oo. 139, p.355- 372, abr.jun., 2017

PALMA FILHO, João C. A Educação Brasileira no período de 1930 a 1960: a era Vargas. Pedagogia Cidadã. Cadernos de Formação. História da Educação. 3. ed. São Paulo: PROGRAD/UNESP- Santa Clara Editora, 2005.

SAVIANI, D. O Plano de Desenvolvimento da Educação: análise do projeto do MEC. Educ. Soc., Campinas, v. 28, n. 100 - Especial, p. 1231-1255, out. 2007.

Data da submissão: 26/11/2018

Data da aprovação: 11/12/2019 